\title{
Monitoring of ammonia in an aqueous environment using a supercontinuum-based photoacoustic sensing system
}

Dasa, Manoj Kumar; Adamu, Abubakar Isa; Janting, Jakob; Kwarkye, Kyei; Markos, Christos; Bang, Ole

\section{Published in:}

Proceedings of SPIE

Link to article, DOI:

$10.1117 / 12.2510351$

Publication date:

2019

Document Version

Publisher's PDF, also known as Version of record

Link back to DTU Orbit

Citation (APA):

Dasa, M. K., Adamu, A. I., Janting, J., Kwarkye, K., Markos, C., \& Bang, O. (2019). Monitoring of ammonia in an aqueous environment using a supercontinuum-based photoacoustic sensing system. In Proceedings of SPIE (Vol. 10895). [108950L] SPIE - International Society for Optical Engineering. Proceedings of SPIE - The International Society for Optical Engineering https://doi.org/10.1117/12.2510351

\section{General rights}

Copyright and moral rights for the publications made accessible in the public portal are retained by the authors and/or other copyright owners and it is a condition of accessing publications that users recognise and abide by the legal requirements associated with these rights.

- Users may download and print one copy of any publication from the public portal for the purpose of private study or research.

- You may not further distribute the material or use it for any profit-making activity or commercial gain

- You may freely distribute the URL identifying the publication in the public portal 


\section{Monitoring of ammonia in an aqueous environment using a supercontinuum-based photoacoustic sensing system}

Manoj Kumar Dasa, Abubakar I. Adamu, Jakob Janting, Kyei Kwarkye, Christos Markos, et al.

Manoj Kumar Dasa, Abubakar I. Adamu, Jakob Janting, Kyei Kwarkye, Christos Markos, Ole Bang, "Monitoring of ammonia in an aqueous environment using a supercontinuum-based photoacoustic sensing system," Proc. SPIE 10895, Frontiers in Biological Detection: From Nanosensors to Systems XI, 108950L (7 March 2019); doi: 10.1117/12.2510351

SPIE. Event: SPIE BiOS, 2019, San Francisco, California, United States 


\title{
Monitoring of Ammonia in an aqueous environment using a supercontinuum-based Photoacoustic Sensing System
}

\author{
Manoj Kumar Dasa, ${ }^{1 *}$ Abubakar I. Adamu, ${ }^{1 *}$ Jakob Janting, ${ }^{1}$ Kyei Kwarkye, ${ }^{1}$ \\ Christos Markos, ${ }^{1}$ and Ole Bang, ${ }^{1,2}$ \\ ${ }^{1}$ DTU Fotonik, Department of Photonics Engineering, Technical University of \\ Denmark, Kgs. Lyngby 2800, Denmark \\ ${ }^{2}$ NKT Photonics, Blokken 84, Birkerød 3460, Denmark \\ *equal contributions_manda@fotonik.dtu.dk,_abisa@fotonik.dtu.dk
}

\section{ABSTRACT}

We demonstrate a robust photoacoustic medium for measuring the concentration of ammonia in an aqueous solution. We target the near-infrared (NIR) overtone absorption band $(1540 \mathrm{~nm})$ of ammonia with a supercontinuum (SC) laser-based excitation system and an immersion-based acoustic transducer as the detection system. We further present how such a simple system can be used to perform effective in-situ measurements of ammonia over a range of concentrations with a sensitivity of parts per million (ppm) by volume and linearity of $>96 \%$. We demonstrate how the sensing system can be readily tailored to monitor the concentrations of other miscible gases in the aqueous solution.

\section{INTRODUCTION}

Monitoring of ammonia concentrations in water is of high importance in many areas, such as fishery and water treatment plants, where rapid changes in concentrations could result in serious complications. In fishery, for example, low levels of ammonia concentration can expose the fish to bacterial infection and a high concentration can have lethal effects. Therefore, there is an inevitable need for accurate and real-time measurement of ammonia concentrations. Most of the established techniques for the detection of ammonia concentrations are either based on enzymatic reactions (delayed response time) or are not readily implementable in aqueous environments ${ }^{1-3}$.

Laser-based sensing systems have widely been the focus of trace detection research and development recently. Due to the presence of fundamental molecular absorption bands, much of the work has been done in the mid-infrared (MIR) region of the electromagnetic spectrum. However, ammonia also shows dominant absorption characteristics in the NIR due to the rotational-vibrational transitions in the combination band $\left(v_{1}+v_{3}\right)$ and the overtone $\left(2 v_{3}\right)^{4-10}$. Photoacoustic sensing (PAS) in particular provides an interesting capability to monitor concentrations of various trace elements like ammonia not only based on its absorption capabilities but also based on the physical properties of the trace elements ${ }^{11,12}$.

In this work, we present how a SC laser built using the dispersion properties of a telecommunication range fiber can be used to build a photoacoustic sensing system (PAS) for measuring the concentration of ammonia in an aqueous solution ${ }^{13,14}$. We target the dominant absorption characteristics of ammonia present due to the rotational-vibrational transitions in the combination band $\left(v_{1}+v_{3}\right)$ and the overtone $\left(2 v_{3}\right)$ bands. We further demonstrate how such a PAS system can be 
used to perform effective in-situ measurements of ammonia over a range of concentrations with a sensitivity of ppm by volume.

\section{EXPERIMENTAL SETUP}

PAS system consists of a fiber-coupled SC laser with a center wavelength of $1550 \mathrm{~nm}$, a repetition rate of $30 \mathrm{kHz}$ emitting output power of $400 \mathrm{~mW}$. The filtered light from the SC source (center wavelength: $\sim 1540 \mathrm{~nm}$, bandwidth: $\sim 30 \mathrm{~nm}$ ) is steered using broadband silver coated mirrors (M1, M2, M3) and focused into the sample holder using an objective lens (L2). Various concentrations of aqueous ammonia were placed in the sample holder. The generated PA signals are detected using immersion based focused transducer with a center frequency of 7.5 MHz. In order to increase the sensitivity of the PAS system, a 3 axis stage is used to confocally align the optical excitation and acoustic detection.

a)

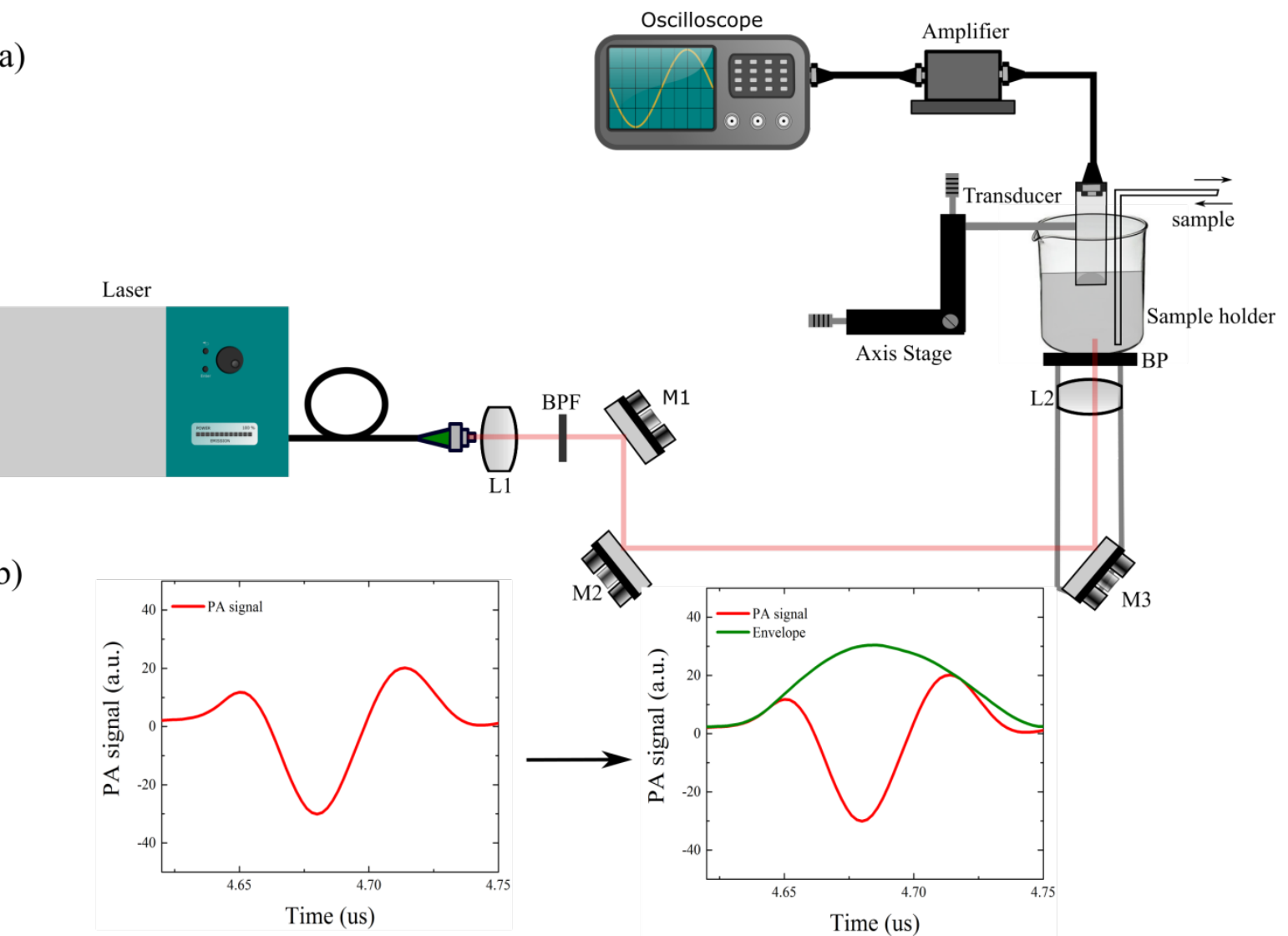

Figure 1: (a) Schematic of the PAS system. Filtered light from an SC laser is used for optical excitation; the output from the laser is collimated using a lens (L1) and then focused inside the sample solution using an objective lens (L2). PA signals are detected using an immersion-based acoustic transducer, amplified using a low-noise amplifier then sent for further data processing. (b) Recorded PA signal and its respective envelope, the PA signal of the sample is the amplitude of the computed envelope.

The detected PA signals are then amplified using low-noise cascaded amplifiers and are subsequently digitized using a high-speed oscilloscope. The analysis of the raw PA signals was 
performed using a MATLAB routine. The routine takes acquired PA signals from each and every concentration of the aqueous ammonia as input. The PA amplitude at the respective concentration was calculated by computing the envelope of the recorded PA signal.

\section{METHODOLOGY}

The maximum pressure $\left(P_{\max }\right)$ generated in the sample with an absorption coefficient $(\alpha)$ due to the laser excitation of an energy $\left(\mathrm{E}_{0}\right)$ can be written as ${ }^{11,12}$,

$$
P_{\max }=K \Gamma \alpha E_{0}
$$

Where $\Gamma$ is Grueneisen parameter, which is a function of expansion coefficient $(\beta)$, specific heat capacity of the sample $\left(C_{P}\right)$ and velocity of ultrasound inside the sample $\left(v_{a}\right)$

Assuming the attenuation of the acoustic wave inside the sample as very small, the amplitude of the PA signal detected by the focused acoustic transducer with a conversion efficiency $(\eta)$, placed at a focal distance from the point of excitation can be written as,

$$
\begin{gathered}
P A_{\text {sig. }}=\eta \cdot P_{\max } \\
P A_{\text {sig. }}=K^{\prime} \Gamma \alpha E_{0}
\end{gathered}
$$

Where $K^{\prime}$ is a constant including the geometrical and response properties of the acoustic transducer. For concentration monitoring experiments, change in the concentration of the sample affects the physical parameters $\left(\beta, C_{P}\right.$ and $\left.v_{a}\right)$ and the absorption coefficient $(\alpha)$ of the sample, thereby affecting the amplitude of the PA signal.

\section{RESULTS AND DISCUSSION}

Figure 2 shows the simulated absorbance of ammonia (solid line) in the overtone band using HITRAN database ${ }^{15}$. The simulations depict the dominant absorption features of ammonia in 1530$1545 \mathrm{~nm}$ wavelength regime. In order to target multiple absorption peaks, the output from the SC laser is filtered using a BPF. The filtered output spectrum of the SC laser is plotted in figure 2 (dash line).

PAS experiments were performed by exciting the overtone band of various concentrations of aqueous ammonia using a $1540 \mathrm{~nm}$ excitation band. Initially, $165 \mathrm{ppm}$ by volume of ammonia solution was used as a starting sample. The sample was excited using the filtered SC and the PA amplitude of the sample was subsequently recorded. The experiment was repeated for ten different concentrations (prepared by diluting the ammonia solution using distilled water).

Figure 3 (a) shows the computed envelopes of recorded PA signals at four different aqueous ammonia concentrations $(165,120,90$ and $80 \mathrm{ppm})$. It can be clearly observed that the amplitude of the recorded PA signal changes with the change in concentration of ammonia inside the aqueous ammonia solutions which can be attributed to the change in absorption coefficient. Figure 3 (b) shows the variation of ammonia concentration with respect to the PA amplitude measured using the PAS system. The dataset shows the expected linear relationship between the PA amplitude and 
ammonia concentrations. Linear regression applied to the dataset yields coefficient of determination of about 0.963 , thereby exhibiting the potential of the PAS system for various concentration monitoring applications.

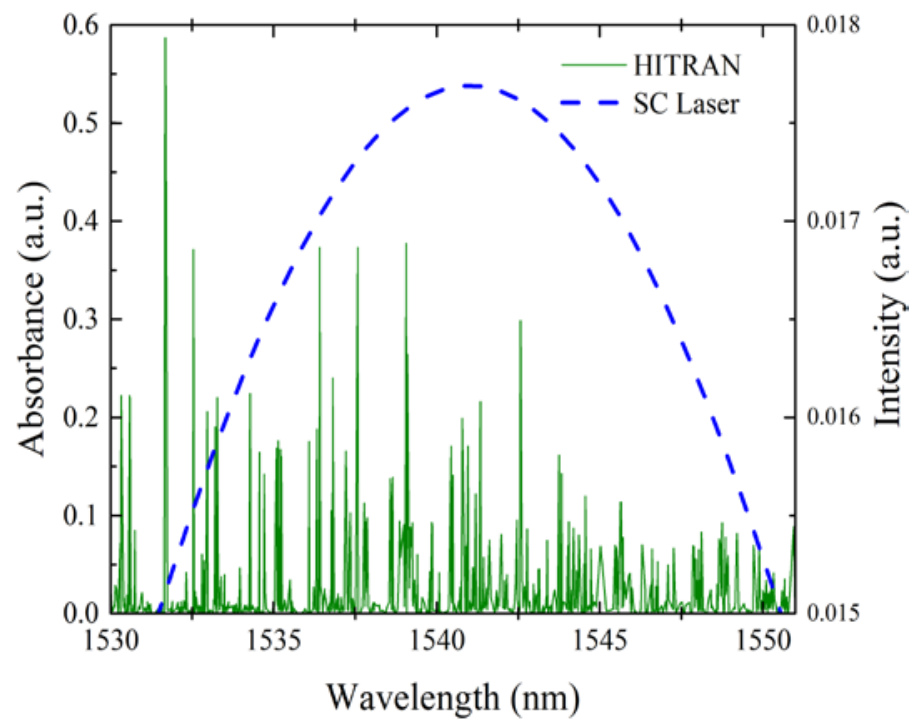

Figure 2: Simulated absorbance of ammonia using the HITRAN database (solid line) in 1530-1550 nm wavelength region. Filtered output spectrum of the SC laser used for excitation (dash line).

Another observation which can be made from figure 3 is, changing the concentration affects the time of flight (time taken by the acoustic wave to reach from the point of origin to the transducer) of the generated PA signal. Changing the concentration of ammonia inside the aqueous solution changes the physical properties of the solution, thereby changing the speed with which the generated acoustic wave travels inside the solution. Figure 4 shows the variation of ammonia concentration with respect to the time delay and the computed velocity of acoustic wave inside the solution.
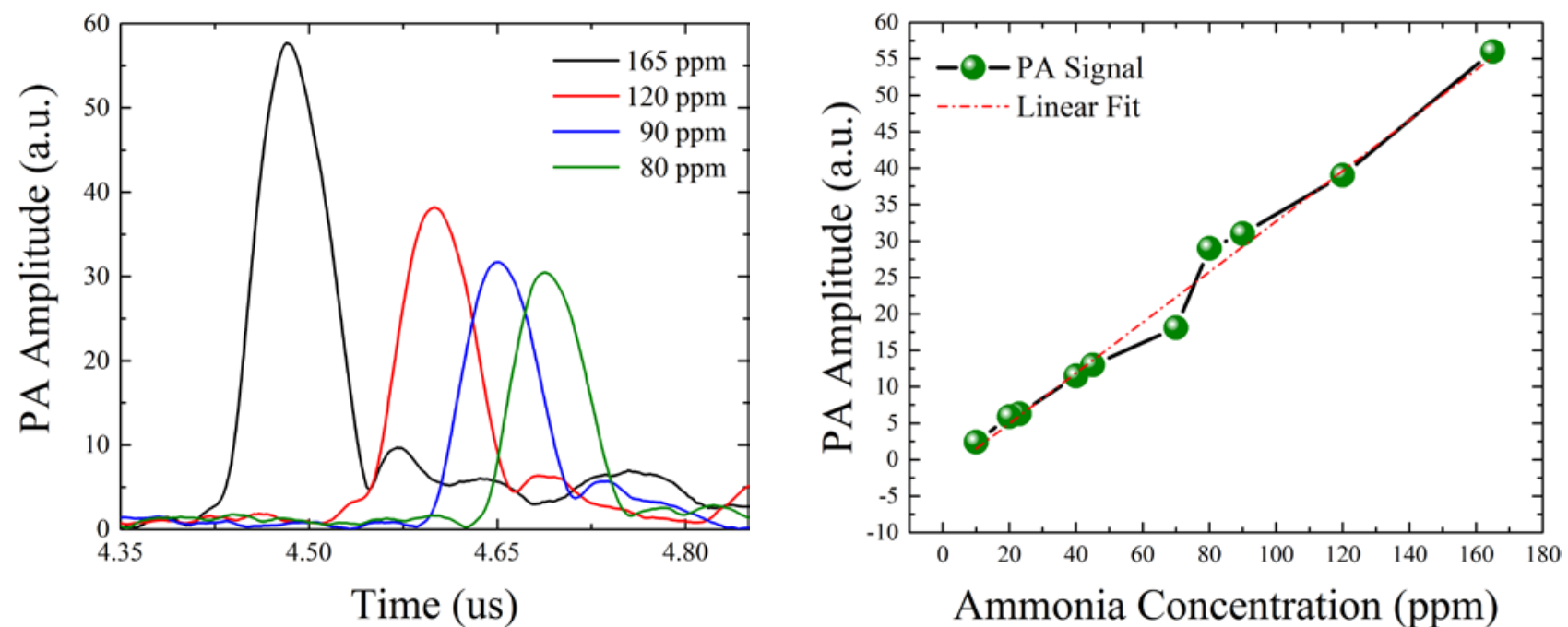

Figure 3: (a) Envelope of the recorded PA signals at four different aqueous ammonia concentrations. (b) Variation of PA amplitude as a function of ammonia concentration. 


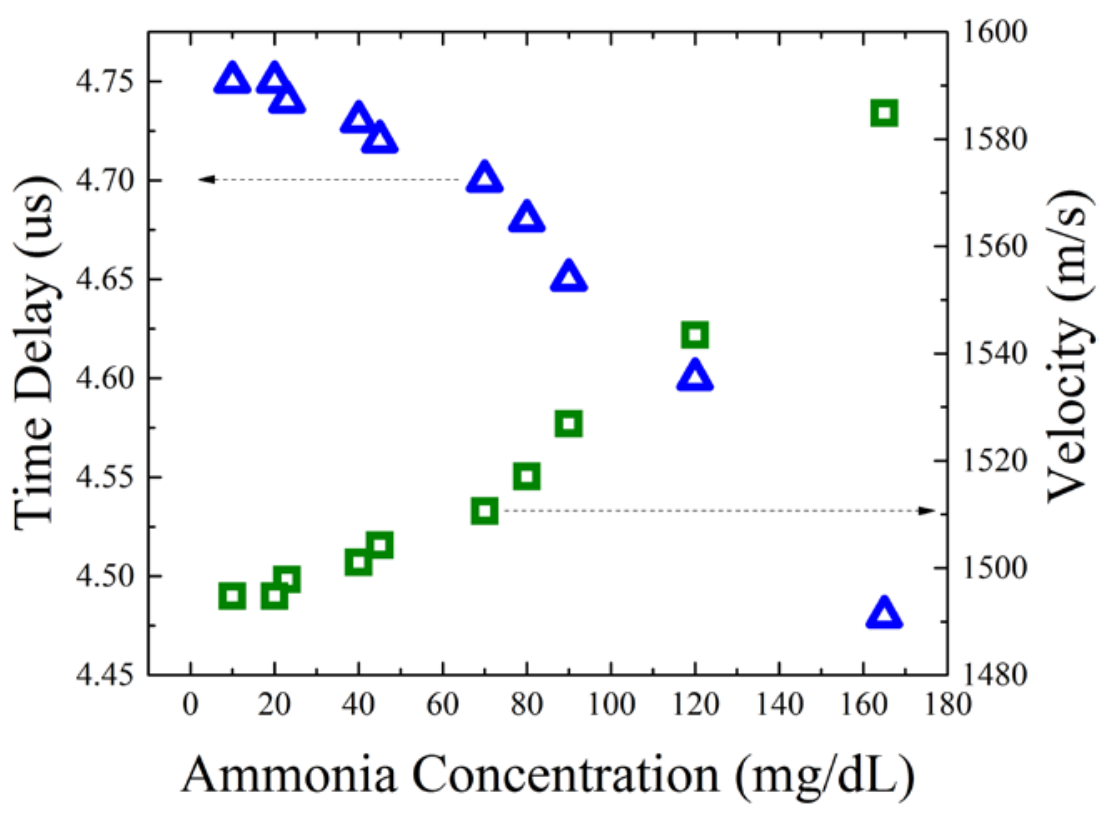

Figure 4: Variation of the time delay and the acoustic velocity with respect to the ammonia concentration inside the sample.

\section{CONCLUSION}

We present a robust system for accurate monitoring and quantitative analysis of ammonia concentration in the aqueous solution, this is of great importance to many areas such as fishery where the changes in the concentration of ammonia can lead to lethal consequences. The proposed system comprises of an SC laser-based excitation system and an immersion-based acoustic transducer as the detection system. We demonstrated how such a simple system can be used to perform real-time in-situ measurements of ammonia inside the distilled water over a range of concentrations, with sub-ppm sensitivity and a linearity $>96 \%$.

\section{ACKNOWLEDGMENTS}

The research project leading to this work has received funding from the European Union's Horizon 2020 research and innovation programme under the Marie Sklodowska-Curie grant agreement No. 722380. C.M. acknowledges the financial support from the Danish Council for Independent Research (4184-00359B) (8022-00091A).

\section{REFERENCES}

1. G. R. Smart, "Investigations of the toxic mechanisms of ammonia to fish-gas exchange in rainbow trout (Salmo gairdneri) exposed to acutely lethal concentrations," Journal of Fish Biology 12 (1), 93-104 (1978).

2. C. E. Bower and T. Holm Hansen, "A salicylate-hypochlorite method for determining ammonia in seawater," Canadian Journal of Fisheries and Aquatic Sciences 37 (5), 794-798 (1980). 
3. L. Adrian, B. Gilles, G. Josette, G. Bruna, L. Luis, R. Stefan, S. David, A. S. Mark, V. Wim, W. Franz, "Impacts of European livestock production: Nitrogen, sulphur, phosphorus and greenhouse gas emissions, land-use, water eutrophication and biodiversity". Environ. Res. Lett. 10, 115004 (2015)

4. R. F. Curl and F. K. Tittel, “Tunable infrared laser spectroscopy,” Annu. Rep. Prog. Chem. Sect. C 98, 217-270 (2002).

5. B. Timmer, W. Olthuis and A. van den Berg, "Ammonia sensors and their applications-a review”. Sens. Actuators B Chem. 107, 666-677 (2005).

6. M. Ohtsu, H. Kotani, and H. Tagawa, "Spectral measurements of NH3 and H2O for pollutant gas monitoring by 1.5 um In-GaAsyInP lasers,” Jpn. J. Appl. Phys. 22, 1553-1557 (1983).

7. M. Feher, P. A. Martin, A. Rohrbacher, A. M. Soliva, and J. P. Maier, "Inexpensive nearinfrared diode-laser-based detection system for ammonia,” Appl. Opt. 32, 2028-2030 (1993).

8. G. Modugno and C. Corsi, "Water vapour and carbon dioxide interference in the high sensitivity detection of NH3 with semiconductor diode lasers at 1.5 um," Infrared Phys. Technol. 40, 93-99 (1999).

9. A. Kosterev and F. K. Tittel, “Ammonia detection using quartz enhanced photoacoustic spectroscopy with a near-IR telecommunication diode laser," Appl. Opt. 43, 6213-6217 (2004).

10. R. Claps, F. V. Englich, D. P. Leleux, D. Richter, F. K. Tittel, and R. F. Curl, "Ammonia detection by use of near-infrared diode-laser-based overtone spectroscopy,” Appl. Opt. 40, 4387- 4394 (2001).

11. C. K. N. Patel and A. C. Tam, "Pulsed optoacoustic spectroscopy of condensed matter," Rev. Mod. Phys. 53, 517-550 (1981).

12. M K. Dasa, C. Markos, J. Janting and O. Bang, "Multispectral photoacoustic sensing for accurate glucose monitoring using a supercontinuum laser”, JOSA B. 36 (2), A61-A65 (2019).

13. M. K. Dasa, C. Markos, M. Maria, C. R. Petersen, P. M. Moselund, and O. Bang, "Highpulse energy supercontinuum laser for high-resolution spectroscopic photoacoustic imaging of lipids in the 1650-1850 nm region,” Biomed. Opt. Express 9, 1762-1770 (2018).

14. C. Markos, J. C. Travers, A. Abdolvand, B. J. Eggleton, and O. Bang, "Hybrid photoniccrystal fiber," Rev. Mod. Phys. 89 (4), 045003 (2017).

15. L. S. Rothman, C. P. Rinsland, A. Goldman, S. T. Massie, D. P. Edwards, J.-M. Flaud, A. Perrin, C. Camy-Peyret, V. Dana, J.-Y. Mandin, J. Schroeder, A. McCann, R. R. Gamache, R. B. Wattson, K. Yoshino, K. V. Chance, K. W. Jucks, L. R. Brown, V. Nemtchinov, and P. Varanasi, "The HITRAN molecular spectroscopic database and HAWKS HITRAN atmospheric workstation!: 1996 edition,” J. Quant. Spectrosc. Radiat. Transfer 60, 665-710 (1998). 